\title{
Effects of Different Palliative Jaundice Reducing Methods on Immunologic Functions in Patients with Advanced Malignant Obstructive Jaundice
}

\author{
KUN TANG, LU-LU SUI, GANG XU, TONG ZHANG, QIANG LIU and XIAO-FANG LIU \\ Department of Hepatobiliary Surgery, Affiliated Yantai Yuhuangding Hospital, \\ Qingdao University Medical College, Yantai, P.R. China
}

\begin{abstract}
Background/Aim: This study aimed to investigate the effects of three treatment methods on the immunological function of patients with advanced malignant obstructive jaundice (MOJ). Patients and Methods: Patients with advanced MOJ were randomly divided into three groups according to biliary drainage methods. Detection of levels of multi-indices were investigated in different time periods. Results: After drainage, the levels of complement 3 (C3) and complement 4 (C4) were increased. Forteen days postoperation, the levels of immunoglobulin $G$ ( $\operatorname{Ig} G)$, immunoglobulin A (IgA) and immunoglobulin $M(\operatorname{IgM})$ in the group undergoing palliative surgery decreased significantly compared to those in both percutaneous transhepatic cholangio drainage (PTCD) and endoscopic retrograde biliary drainage (ERBD) groups. The level of serum endotoxin in the group undergoing palliative surgery decreased gradually. Conclusion: Palliative surgery for reducing jaundice is superior to PTCD and ERBD in improving immune function of patients with MOJ.
\end{abstract}

Malignant obstructive jaundice (MOJ) is a form of jaundice that develops due to intrahepatic cholestasis when the internal and external bile ducts are obstructed because of compression or invasive growth of malignant tumors $(1,2)$. The disease is often asymptomatic in its early stages so it is often only discovered in the middle and advanced stages. Moreover, the 5-year survival rate of patients is only 5-8\% (3). The hyperbilirubinemia and endotoxemia caused by the bile duct obstruction not only damage liver function, but also

Correspondence to: Dr. Xiao-Fang Liu, Department of Hepatobiliary Surgery, Affiliated Yantai Yuhuangding Hospital, Qingdao University Medical College, Yantai, P.R. China. Tel: +86 5356691999, Fax: +86 5356240341, e-mail: Liu634@263.net

Key Words: Malignant obstructive jaundice, drainage, immunologic function, endotoxin. inhibit the cellular and humoral immune functions of the human body, especially the cellular immune function, which is significantly reduced (4-7).

This study retrospectively compared and analyzed the main indicators of human immunological function namely, changes of complement $\mathrm{C} 3$ and $\mathrm{C} 4$, immunoglobulin $\mathrm{IgG}$, $\operatorname{IgA}$, and $\operatorname{IgM}$ and endotoxin, among patients with advanced MOJ who underwent palliative surgery for reducing jaundice, percutaneous transhepatic cholangial drainage (PTCD) and endoscopic retrograde biliary drainage (ERBD) respectively, from September 2011 to September 2015. Based on this information we explored the effect of internal and external biliary drainage for MOJ on the immune function of the human body and provided a basis for selecting reasonable biliary drainage methods for patients with advanced MOJ.

\section{Materials and Methods}

General information and grouping. A total of 271 patients (143 males and 128 females from 41 to 85 years with an average age of $67.4 \pm 6.3$ years) with advanced MOJ were enrolled at The Affiliated Yantai Yuhuangding Hospital of Qingdao University from September 2011 to September 2015. All patients were diagnosed with extrahepatic bile duct malignant obstruction as confirmed by examinations such as B-ultrasound, computed tomography (CT), magnetic resonance imaging (MRI), or magnetic resonance cholangiopancreatography (MRCP).

Preoperative total bilirubin of all patients was in the range of $105.2-489.4 \mu \mathrm{mol} / \mathrm{L}$, with a mean value of $231.34 \pm 7.13 \mu \mathrm{mol} / \mathrm{l}$. This study was approved by the hospital's ethics committee, and the patients voluntarily participated and signed informed consent forms.

Using computer-generated random number table according to the time the patient admitted to the hospital, they were randomly divided into the following three groups according to biliary drainage methods: group A-95 patients undergoing palliative surgery for reducing jaundice; group B-95 patients undergoing PTCD; and group C-84 patients undergoing ERBD. No patients were treated with chemotherapy, radiotherapy, or other immunotherapy during the course of the study and patients with immune system diseases were excluded. 
Causes and obstruction site. There were 92 patients with cholangiocarcinoma, 85 patients with pancreatic head cancer, 78 patients with periampullary carcinoma, 14 patients with bile duct obstruction due to lymph node metastasis of malignant gastrointestinal tumors, and 2 patients with bile duct obstruction caused by lymphoma.

Specimen collection. Four milliliters of fasting peripheral venous blood was collected in the morning from each patient 1 day before operation as well as 3,7 and 14 days after operation. Peripheral venous blood $(2 \mathrm{ml})$ was placed in a sterile test tube, kept in an incubator at $37^{\circ} \mathrm{C}$ for $30 \mathrm{~min}$ and centrifuged for $10 \mathrm{~min}$ at 3,000 $\mathrm{rpm}$ within $1 \mathrm{~h}$ to extract the serum for the detection of complement $\mathrm{C} 3$ and $\mathrm{C} 4$ and immunoglobulin $\operatorname{IgG}, \operatorname{IgA}$, and $\operatorname{IgM}$. Peripheral venous blood $(2 \mathrm{ml})$ was then injected into the heparin anticoagulant tube to be centrifuged for $5 \mathrm{~min}$ at $3,000 \mathrm{rpm}$ in order to extract the serum for detection of endotoxin.

Detection methods. An automatic specific protein analyzer was used (BN ProSpecSystem. Siemens Healthcare Diagnostics, Marburg, Germany) to detect complement $\mathrm{C} 3$ and $\mathrm{C} 4$ and immunoglobulin $\mathrm{IgG}, \operatorname{Ig} \mathrm{A}$, and $\operatorname{IgM}$ according to the immune turbidimetry method. The microorganism dynamic and rapid detection system (Beijing Jinshanchuan Technology Development Co., LtdBeijing, P.R.China) was used to detect the endotoxin according to the rapid, quantitative, and dynamic turbidimetric method. Color ultrasound machine with a probe frequency of $3.5 \mathrm{MHz}$ was used; a $7-8 \mathrm{~F}$ porous catheter with a pin core was purchased from Taiwan Bioteque Corporation.

Treatment methods. The method used for palliative surgery for reducing jaundice involved bile duct-jejunum anastomosis, gallbladder-jejunum anastomosis, intrahepatic bile duct jejunum bridge drainage, and common bile duct- duodenum anastomosis.

$P T C D$. The expanded intrahepatic bile duct was selected with B ultrasound positioning, and the puncture needle entered the preselected bile duct under the guidance of ultrasound.

$E R B D$. The patient fasted on the day of surgery, and endoscopic retrograde cholangio pancreatography (ERCP) was carried out routinely. The catheter was intubated through the duodenal papilla, and iohexol was used for contrast radiography. The location and scope of biliary stenosis was observed; a guide wire was indwelled, and then the dilating bougie was sent slowly into the narrowed area through the guide wire for expansion. The upper end of the biliary stent was subsequently passed across the stenosis segment by $2 \mathrm{~cm}$ and the lower end of the biliary stent was exposed outside the papilla by $0.5 \mathrm{~cm}$. Finally, endoscopic sphincterotomy (EST) was carried 6 out to prevent the occurrence of acute pancreatitis.

Statistical analysis. Statistical analysis was performed using SPSS v23.0 statistical software. The measurement data were expressed as mean \pm standard deviation $(\bar{X} \pm \mathrm{s})$. Pearson $\chi^{2}$ test was used to compare the differences between the groups. One-way ANOVA was used to compare the differences between the three groups. The pairwise comparison was performed with LSD test. Single factor ANOVA with repeated measures was used to compare the differences within each group and statistical significance was reached at $p<0.05$.
Table I. Comparison of the general conditions among three groups of patients $(\bar{X} \pm s)$.

\begin{tabular}{llllllll}
\hline Group Cases & $\begin{array}{c}\text { Age } \\
(\text { years })\end{array}$ & \multicolumn{2}{c}{ Gender } & & Preoperative bilirubin level \\
\cline { 7 - 8 } & & & & Male Female & & $\begin{array}{c}\text { TBil } \\
(\mu \mathrm{mol} / \mathrm{L})\end{array}$ & $\begin{array}{c}\text { DBil } \\
(\mu \mathrm{mol} / \mathrm{L})\end{array}$ \\
\hline $\mathrm{A}$ & 95 & $67.1 \pm 6.4$ & 50 & 45 & & $233.15 \pm 11.13$ & $158.22 \pm 10.25$ \\
$\mathrm{~B}$ & 92 & $68.3 \pm 6.1$ & 48 & 44 & & $230.54 \pm 10.52$ & $157.34 \pm 10.13$ \\
$\mathrm{C}$ & 84 & $66.8 \pm 5.7$ & 45 & 39 & & $231.23 \pm 10.34$ & $159.29 \pm 9.97$ \\
\hline
\end{tabular}

\section{Results}

Comparison of general conditions. All patients completed the treatment, and no adverse reactions occurred. These clinical factors were following normal distribution. In group A, 95 patients (50 males and 45 females from 41 to 75 years with an average age of $67.1 \pm 6.4$ years) underwent palliative surgery for reducing jaundice; their preoperative total bilirubin was in the range of 105.2-391.3 $\mu \mathrm{mol} / \mathrm{L}$ with a mean value of $233.15 \pm 11.13 \mu \mathrm{mol} / 1$, and direct bilirubin was in the range of $65.9-288.7 \mu \mathrm{mol} / \mathrm{l}$ with a mean value of $158.22 \pm 10.25 \mu \mathrm{mol} / 1$.

In group B, 92 patients (48 males and 44 females from 43 to 85 years with an average age of $68.3 \pm 6.1$ years) underwent PTCD; their preoperative total bilirubin was in the range of $173.8-489.4 \mu \mathrm{mol} / 1$ with a mean value of $230.54 \pm 10.52 \mu \mathrm{mol} / 1$, and the direct bilirubin was in the range of $121.3-354.8 \mu \mathrm{mol} / \mathrm{L}$ with a mean value of $157.34 \pm 10.13 \mu \mathrm{mol} / 1$.

In group C, 84 patients ( 45 males and 39 females from 44 to 84 years with an average age of $66.8 \pm 5.7$ years) underwent ERBD; their preoperative total bilirubin was in the range of $121.8-418.2 \mu \mathrm{mol} / \mathrm{l}$ with a mean value of $231.23 \pm 10.34 \mu \mathrm{mol} / 1$, and the direct bilirubin was in the range of $97.7-319.1 \mu \mathrm{mol} / \mathrm{l}$ with a mean value of

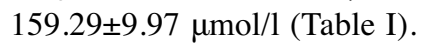

The Pearson $\chi^{2}$ test showed that there was no significant difference in the sex composition between the three groups $\left(\chi^{2}=0.035, p=0.982\right)$. The one-way analysis of variance showed that there were no significant differences in the age, preoperative total bilirubin, and direct bilirubin levels among the three groups ( $\mathrm{F}$ values were 1.528,1.497, and 0.815, respectively $(p>0.05)$.

Changes in the levels of complement C3 and C4. After drainage, the levels of complement C3 and C4 were increased in the three groups to varying degrees, and there were statistically significant differences $(p<0.05)$; the levels of complement $\mathrm{C} 3$ and $\mathrm{C} 4$ in the ERBD group were 
Table II. Comparison of expression levels of serum complement $C 3$ at different times among three groups of patients $(\bar{X} \pm s)$.

\begin{tabular}{lcccc}
\hline Group & \multicolumn{4}{c}{ Complement C3 (g/l) (0.90-1.80) } \\
\cline { 2 - 5 } & $\begin{array}{c}\text { 1st day } \\
\text { preoperation }\end{array}$ & $\begin{array}{c}\text { 3rd day } \\
\text { postoperation }\end{array}$ & $\begin{array}{c}\text { 7th day } \\
\text { postoperation }\end{array}$ & $\begin{array}{c}\text { 14th day } \\
\text { postoperation }\end{array}$ \\
\hline A & $0.52 \pm 0.21$ & $0.65 \pm 0.25$ & $1.24 \pm 0.24 \mathrm{ab}$ & $1.33 \pm 0.25^{\mathrm{ab}}$ \\
B & $0.55 \pm 0.23$ & $0.63 \pm 0.20$ & $0.87 \pm 0.19$ & $0.95 \pm 0.21$ \\
C & $0.53 \pm 0.24$ & $0.69 \pm 0.22$ & $1.11 \pm 0.27$ & $1.20 \pm 0.25$ \\
F-value & 0.423 & 1.611 & 59.553 & 61.659 \\
$p$-value & 0.655 & 0.202 & $<0.001$ & $<0.001$ \\
\hline
\end{tabular}

Group A: Undergoing palliative surgery for reducing jaundice; Group B: undergoing PTCD; Group C: undergoing ERBD, compared with Group B, ${ }^{\mathrm{a}} p<0.05$; compared with Group $\mathrm{C},{ }^{\mathrm{b}} p<0.05$.

Table III. Comparison of expression levels of serum complement $C 4$ at different times among three groups of patients $(\bar{X} \pm s)$.

\begin{tabular}{lcccc}
\hline Group & \multicolumn{4}{c}{ Complement C4 (g/l) (0.20-0.60) } \\
\cline { 2 - 5 } & $\begin{array}{c}\text { 1st day } \\
\text { preoperation }\end{array}$ & $\begin{array}{c}\text { 3rd day } \\
\text { postoperation }\end{array}$ & $\begin{array}{c}\text { 7th day } \\
\text { postoperation }\end{array}$ & $\begin{array}{c}\text { 14th day } \\
\text { postoperation }\end{array}$ \\
\hline A & $0.171 \pm 0.012$ & $0.196 \pm 0.014$ & $0.445 \pm 0.019 \mathrm{ab}$ & $0.515 \pm 0.027 \mathrm{ab}$ \\
B & $0.169 \pm 0.013$ & $0.198 \pm 0.013$ & $0.317 \pm 0.015$ & $0.323 \pm 0.015$ \\
C & $0.170 \pm 0.014$ & $0.201 \pm 0.014$ & $0.361 \pm 0.018$ & $0.481 \pm 0.014$ \\
F-value & 0.554 & 3.002 & 1304.352 & 2462.898 \\
$p$-value & 0.575 & 0.051 & $<0.001$ & $<0.001$ \\
\hline
\end{tabular}

Group A: Undergoing palliative surgery for reducing jaundice; Group $\mathrm{B}$ : undergoing PTCD; Group C: undergoing ERBD, compared with Group B, ${ }^{\mathrm{a}} p<0.05$; compared with Group C, ${ }^{\mathrm{b}} p<0.05$.

increased significantly on the 3rd day after operation, but there were no statistical differences compared to the groups undergoing palliative surgery for reducing jaundice and PTCD, respectively $(p>0.05)$. The levels of complement C3 and $\mathrm{C} 4$ in the group undergoing palliative surgery for reducing jaundice were increased significantly on the 7th and 14th day after operation. Moreover, there were significant differences compared to both the ERBD and PTCD groups $(p<0.001)$ (Tables II and III).

Changes in the levels of immunoglobulin $\operatorname{Ig} G, \operatorname{IgA}$ and $\operatorname{Ig} M$. The levels of $\operatorname{IgG}, \operatorname{IgA}$, and $\operatorname{IgM}$ in the group undergoing palliative surgery for reducing jaundice were increased slightly on the 3rd day after the drainage compared with the pre-operations. Moreover, there were statistical differences compared with both the ERBD and PTCD groups $(p<0.001)$;
Table IV. Comparison of expression levels of serum immunoglobulin $\operatorname{Ig} G$ at different times among three groups of patients $(\bar{X} \pm s)$.

\begin{tabular}{lcccc}
\hline Group & \multicolumn{4}{c}{$\operatorname{IgG}(\mathrm{g} / \mathrm{l})(7.00-16.00)$} \\
\cline { 2 - 5 } & $\begin{array}{c}\text { 1st day } \\
\text { preoperation }\end{array}$ & $\begin{array}{c}\text { 3rd day } \\
\text { postoperation }\end{array}$ & $\begin{array}{c}\text { 7th day } \\
\text { postoperation }\end{array}$ & $\begin{array}{c}\text { 14th day } \\
\text { postoperation }\end{array}$ \\
\hline $\mathrm{A}$ & $12.35 \pm 1.34$ & $14.45 \pm 2.01 \mathrm{ab}$ & $8.31 \pm 1.84$ & $7.25 \pm 1.45^{\mathrm{ab}}$ \\
$\mathrm{B}$ & $12.12 \pm 2.11$ & $10.01 \pm 1.59$ & $8.63 \pm 1.58$ & $7.95 \pm 1.95$ \\
$\mathrm{C}$ & $11.79 \pm 3.59$ & $10.32 \pm 2.31$ & $8.45 \pm 2.13$ & $7.71 \pm 1.72$ \\
F-value & 1.145 & 145.210 & 0.698 & 4.020 \\
$p$-value & 0.320 & $<0.001$ & 0.498 & 0.019 \\
\hline
\end{tabular}

Group A: Undergoing palliative surgery for reducing jaundice; Group B: undergoing PTCD; Group C: undergoing ERBD, compared with group $\mathrm{B} ;{ }^{\mathrm{a}} p<0.05$; compared with group $\mathrm{C},{ }^{\mathrm{b}} p<0.05$.

Table V. Comparison of expression levels of serum immunoglobulin IgA at different times among three groups of patients $(\bar{X} \pm s)$.

\begin{tabular}{lcccc}
\hline Group & \multicolumn{4}{c}{ Immunoglobulin IgA (g/l) (0.70-4.00) } \\
\cline { 2 - 5 } & $\begin{array}{c}\text { 1st day } \\
\text { preoperation }\end{array}$ & $\begin{array}{c}\text { 3rd day } \\
\text { postoperation }\end{array}$ & $\begin{array}{c}\text { 7th day } \\
\text { postoperation }\end{array}$ & $\begin{array}{c}\text { 14th day } \\
\text { postoperation }\end{array}$ \\
\hline $\mathrm{A}$ & $3.21 \pm 0.21$ & $3.74 \pm 0.25 \mathrm{ab}$ & $2.19 \pm 0.33$ & $1.74 \pm 0.21^{\mathrm{ab}}$ \\
$\mathrm{B}$ & $3.19 \pm 0.34$ & $2.31 \pm 0.28$ & $2.14 \pm 0.26$ & $1.96 \pm 0.27$ \\
$\mathrm{C}$ & $3.15 \pm 0.27$ & $2.23 \pm 0.33$ & $2.21 \pm 0.31$ & $1.94 \pm 0.38$ \\
F-value & 1.064 & 809.985 & 1.277 & 16.189 \\
$p$-value & 0.346 & $<0.001$ & 0.281 & $<0.001$ \\
\hline
\end{tabular}

Group A: Undergoing palliative surgery for reducing jaundice; Group B: undergoing PTCD; Group C: undergoing ERBD, compared with Group B; ${ }^{\mathrm{a}} p<0.05$; compared with Group $\mathrm{C},{ }^{\mathrm{b}} p<0.05$.

the levels of $\operatorname{IgG}, \operatorname{IgA}$, and $\operatorname{IgM}$ in both the ERBD and PTCD groups were decreased slightly on the 3rd day after the drainage compared to the levels pre-operation. On the 7th day after operation, the levels of $\operatorname{IgG}, \operatorname{IgA}$, and $\operatorname{IgM}$ were decreased in all three groups, but there were no statistical differences $(p>0.05)$. On the 14th day after operation, the levels of $\operatorname{IgG}, \operatorname{IgA}$, and $\operatorname{IgM}$ in the group undergoing palliative surgery for reducing jaundice were decreased significantly more than those in both PTCD and ERBD groups, $(p<0.001)$ (Tables IV, V and VI).

Changes in the level of serum endotoxin. The level of serum endotoxin in the group undergoing palliative surgery for reducing jaundice was decreased gradually after operation, which reached statistical significance $(p<0.05)$. The levels of endotoxin in both ERBD and PTCD groups were increased 
Table VI. Comparison of expression levels of immunoglobulin IgM at different times among three groups of patients $(\bar{X} \pm s)$.

\begin{tabular}{lcccc}
\hline Group & \multicolumn{4}{c}{ Immunoglobulin $\operatorname{IgM}(\mathrm{g} / \mathrm{l})(0.40-2.30)$} \\
\cline { 2 - 5 } & $\begin{array}{c}\text { 1st day } \\
\text { preoperation }\end{array}$ & $\begin{array}{c}\text { 3rd day } \\
\text { postoperation }\end{array}$ & $\begin{array}{c}\text { 7th day } \\
\text { postoperation }\end{array}$ & $\begin{array}{c}\text { 14th day } \\
\text { postoperation }\end{array}$ \\
\hline $\mathrm{A}$ & $1.69 \pm 0.15$ & $1.98 \pm 0.29 \mathrm{ab}$ & $1.61 \pm 0.21$ & $1.41 \pm 0.24 \mathrm{ab}$ \\
$\mathrm{B}$ & $1.71 \pm 0.23$ & $1.65 \pm 0.22$ & $1.59 \pm 0.19$ & $1.47 \pm 0.23$ \\
$\mathrm{C}$ & $1.65 \pm 0.21$ & $1.61 \pm 0.18$ & $1.63 \pm 0.22$ & $1.54 \pm 0.18$ \\
F-value & 2.059 & 67.799 & 0.823 & 7.816 \\
$p$-value & 0.130 & $<0.001$ & 0.440 & $<0.001$ \\
\hline
\end{tabular}

Group A: Undergoing palliative surgery for reducing jaundice; Group B: undergoing PTCD; Group C: undergoing ERBD, compared with Group B; ${ }^{\mathrm{a}} p<0.05$; compared with Group $\mathrm{C},{ }^{\mathrm{b}} p<0.05$.

Table VII. Comparison of expression levels of serum endotoxin at different times among three groups of patients $(\bar{X} \pm s)$.

\begin{tabular}{lcccc}
\hline Group & \multicolumn{4}{c}{ Serum endotoxin $(\mathrm{pg} / \mathrm{ml})$} \\
\cline { 2 - 5 } & $\begin{array}{c}\text { 1st day } \\
\text { preoperation }\end{array}$ & $\begin{array}{c}\text { 3rd day } \\
\text { postoperation }\end{array}$ & $\begin{array}{c}\text { 7th day } \\
\text { postoperation }\end{array}$ & $\begin{array}{c}\text { 14th day } \\
\text { postoperation }\end{array}$ \\
\hline A & $48.8 \pm 9.2$ & $47.9 \pm 10.3$ & $36.9 \pm 9.7$ & $28.1 \pm 7.5^{\mathrm{cd}}$ \\
B & $49.3 \pm 8.5$ & $50.7 \pm 9.3$ & $35.1 \pm 9.5$ & $37.3 \pm 9.1$ \\
C & $50.1 \pm 8.2$ & $51.2 \pm 10.0$ & $32.7 \pm 10.4^{\mathrm{ab}}$ & $31.1 \pm 8.3$ \\
F-value & 0.507 & 2.976 & 4.057 & 29.566 \\
$p$-value & 0.603 & 0.053 & 0.018 & $<0.001$ \\
\hline
\end{tabular}

Group A: Undergoing palliative surgery for reducing jaundice; Group B: undergoing PTCD; Group C: undergoing ERBD, compared with Group A; ${ }^{\mathrm{a}} p<0.05$; compared with Group $\mathrm{B},{ }^{\mathrm{b}} p<0.05$, compared with Group B, ${ }^{\mathrm{c}} p<0.05$; compared with Group C, ${ }^{\mathrm{d}} p<0.05$.

slightly on the 3rd day after operation, but there was no significant difference $(p>0.05)$, and the levels of endotoxin in both ERBD and PTCD groups were decreased gradually ata later period. On the 7th day after operation, the level of serum endotoxin in the ERBD group was lower than those in the groups undergoing palliative surgery for reducing jaundice and PTCD, and the differences were significant $(p=0.018)$. On the 14 th day after operation, the level of serum endotoxin in the group undergoing palliative surgery for reducing jaundice was lower than those in both ERBD and PTCD groups, and there were significant differences $(p<0.001)$, (Table VII).

\section{Discussion}

MOJ patients are in a severe state of immunological stress during which time inflammatory cytokines are released and immune factors are consumed. Hence cellular-based immune function is decreased (8) and the immune system is inhibited
(9-11). The changes in immune functions of patients are one of the key factors leading to high rates of complications and mortality which affect prognosis (12).

Clinically, only about $80 \%$ of MOJ patients can receive palliative drainage treatment (13). The jaundice-reducing treatment can achieve a certain degree of recovery in immune function so that patients' quality of life is improved and their survival periods increased $(6,7,14-16)$. The effects of other palliative drainage treatments are different $(17,18)$, and the change in immune function is one of the important factors affecting the treatment outcome. In this paper, we explored this subject through detection of multi-indices such as complement $\mathrm{C} 3$ and $\mathrm{C} 4$; immunoglobulin $\mathrm{IgG}, \mathrm{IgA}$, and $\mathrm{IgM}$; and endotoxin.

Liver macrophages and lymphocytes are the main sites where C3 and C4 are produced. Since the functions of macrophages and lymphocytes in MOJ patients are significantly reduced, complement production and levels are consequently decreased. This study found that complement C3 and $\mathrm{C} 4$ levels in three groups were increased to varying degrees after relief of biliary obstruction by drainage. On the 7th and 14th day after operation, the levels of complement C3 and $\mathrm{C} 4$ in the group undergoing palliative surgery for reducing jaundice were increased significantly compared with those in both ERBD and PTCD groups, and there were significant differences $(p<0.001)$. Along with the prolongation of postoperative time, the levels of complement $\mathrm{C} 3$ and $\mathrm{C} 4$ in the group undergoing palliative surgery for reducing jaundice were higher than those in both ERBD and PTCD groups, and the advantage of jaundice-reducing treatment in affecting immune mechanism was gradually manifested.

The immune barrier function of the hepatobiliary system is mainly achieved through macrophages and Ig-producing cells. Macrophages swallow, digest, and remove toxins, bacteria, and other macromolecular antigens in the portal vein. The products of Ig-producing cells are mainly $\operatorname{IgA}$, which combine with a secretory component of its carrier to form a mucin-IgA protective layer on the biliary mucosal surface so as to prevent the antigen from entering into the mucosa and cause allergic reactions.

The IgA discharged into the intestinal tract along with the bile is the main source of intestinal Ig. As the phagocytic ability of liver macrophages in MOJ patients is decreased, the intestinal Ig is dramatically reduced, which leads to intestinal immune defense dysfunction, increased uptake of bacteria, and endotoxin. As a result, the human body produces a large number of inflammatory mediators and cytokines causing various influences on immune functions of the human body.

Ohshio et al. (1990) reported that when the bile duct is obstructed and the permeability of the blood-biliary barrier is increased, the plasma IgA level is significantly increased; when the blood-biliary barrier is improved, the blood IgA 
level is decreased correspondingly (19). Therefore, the serum IgA level (which has a significantly positive correlation with the degree of bile duct obstruction) can be taken as the sensitive indicator for determining the degree of biliary obstruction and the effect of surgical drainage on immunological functions (20).

In the present study, $\operatorname{IgA}, \operatorname{IgG}$, and $\operatorname{IgM}$ levels in the group undergoing palliative surgery for reducing jaundice were increased slightly on the 3rd day after operation compared with the preoperation period. The increase in IgG level was particularly significant. This is considered to be related to postoperative infection and inhibited immune function of the human body caused by the general anesthesia required for laparotomy. On the 14th day after operation, the levels of $\operatorname{IgA}, \operatorname{IgG}$, and $\operatorname{IgM}$ in the group undergoing palliative surgery for reducing jaundice were decreased more significantly compared to both PTCD and ERBD groups. This is considered to be related to surgical drainage, disappeared bilirubinemia and recovered hepatoenteral circulation of bile acid and immune functions.

Studies have shown that endotoxin activity is the main reason for inhibited immunological function in obstructive jaundice. In patients with obstructive jaundice, the bile cannot be successfully discharged into the intestinal tract, thus leading to bile acid and immunoglobulin deficiencies. As a result, growth of Gram-negative bacilli in the intestinal tract becomes excessive, leading to large amounts of endotoxin being produced, which causes intestinal mucosal injury and endotoxemia $(21,22)$.

Endotoxin passes through the portal vein to reach the liver, and a large amount of endotoxin associated with hyperbilirubinemia can inhibit the phagocytic function of liver macrophages. Therefore, as a large amount of endotoxin cannot be removed it enters directly into the systemic circulation to cause systemicendotoxemia, which aggravates the injuries of various organs of the whole body caused by hyperbilirubinemia. The endotoxemia is the result of impaired immune function, which in turn aggravates the damage to the immune system of the human body to form a vicious circle (23).

In this study, we compared the effects of three treatment methods-palliative surgery for reducing jaundice, PTCD, and ERBD on the serum endotoxin levels of patients with malignant obstructive jaundice. The results showed that the serum endotoxin level in the group undergoing palliative surgery for reducing jaundice was decreased gradually after operation, and the serum endotoxin levels in both ERBD and PTCD groups were significantly increased on the 3rd day after operation but were gradually decreased over time.

A comparison of serum endotoxin levels on the 7th day after operation among the three groups showed that the serum endotoxin level in the ERBD group was significantly decreased and was lower than levels in both the group undergoing palliative surgery for reducing jaundice and the PTCD group. Although the specific mechanism still needs further study (24), this is considered to be related to fewer traumas, shorter operation time, less intraoperative bleeding, and internal biliary drainage during the ERCP operation.

The serum endotoxin level on the 14th day after operation was decreased compared with that on the 7 th day after operation in the PTCD group $(p<0.05)$, suggesting that prolonged external drainage may cause exacerbation of endotoxemia. Water electrolyte and acid-base balance disorders and gastrointestinal absorption dysfunction due to the loss of a large amount of bile caused by the external drainage may be the reasons (25). Sano et al. $(26,27)$ found that the intestinal bile is also an important component to maintain human immunity (26); the bile salt can effectively decompose the endotoxin with an inhibiting effect on cellular immune immunity, inhibit the excessive multiplication of intestinal Gram-negative bacteria, reduce the generation of endotoxin, maintain the integrity of the intestinal mucosal barrier, and reduce the incidence of bacterial translocation in obstructive jaundice (27). The study also found that the serum endotoxin level on the 14th day after operation in the group undergoing palliative surgery for reducing jaundice was significantly lower than those in both ERBD and PTCD groups.

The findings mentioned above suggest that, with the extension of postoperative time, the effect of surgical drainage is definite positive, and the postoperative recovery of immune function in the group undergoing palliative surgery for reducing jaundice is better.

\section{Conclusion}

This study shows that palliative surgery for reducing jaundice is superior to PTCD and ERBD in improving immune function of patients with MOJ.For patients with malignant obstructive jaundice who can undergo surgical treatment, it is preferable to use palliative surgery for reducing jaundice. For patients with malignant obstructive jaundice who have lost the opportunity to undergo surgery or cannot tolerate the surgery, it is feasible to carry out PTCD or ERBD to relieve the biliary tract obstruction and improve immunological function, thereby extending the survival time and improving the quality of life.

\section{Conflicts of Interest}

The Authors declare that they have no competing interests.

\section{Acknowledgements}

The work was supported by grants from Natural Science Foundation of Shandong Province, P.R.China (No.ZR2014HM052). 


\section{References}

$1 \mathrm{Ngu} \mathrm{W,} \mathrm{Jones} \mathrm{M,} \mathrm{Neal} \mathrm{CP,} \mathrm{Dennison} \mathrm{AR,} \mathrm{Metcalfe} \mathrm{MS} \mathrm{and}$ Garcea G: Preoperative biliary drainage for distal biliary obstruction and post-operative infectious complications.ANZ J Surgery 83(4): 280-286, 2013.

2 Krokidis $\mathrm{M}$ and Hatzidakis A: Percutaneous minimally invasive treatment of malignant biliary strictures: current status. Cardiovasc Intervent Radiol 37(2): 316-323, 2014.

3 Jemal A, Siegel R, Xu J and Ward E: Cancer statistics, 2010. CA Cancer J Clin 60(5): 277-300, 2010.

4 Wang S, Wang X, Li L, Dai H and Han J: Association of preoperative obstructive jaundice with postoperative infectious complications following pancreaticoduodenectomy. Hepatogastroenterology 60(126): 1274-1279, 2013.

5 Parıldar Z, Çınar C, Barutcuoglu B, Başol G and Parıldar M: Effects of percutaneous transhepatic biliary drainage on renal function in patients with obstructive jaundice. Diagn Interv Radiol 17(1): 74-79, 2011.

6 Iacono C, Ruzzenente A, Campagnaro T, Bortolasi L, Valdegamberi A and Guglielmi A: Role of preoperative biliary drainage in jaundiced patients who are candidates for pancreatoduodenectomy or hepatic resection: highlights and drawbacks. Ann Surg 257(2): 191-204, 2013.

7 Xiong JJ, Nunes QM, Huang W, Pathak S, Wei AL, Tan CL and Liu XB: Preoperative biliary drainage in patients with hilar cholangiocarcinoma undergoing major hepatectomy. World J Gastroenterol 19(46): 8731-8739, 2013.

8 Kawarabayashi N, Seki S, Hatsuse K, Kinoshita M, Takigawa T, Tsujimoto H, Kawabata T, Nakashima H, Shono $S$ and Mochizuki H: Immunosuppression in the livers of mice with obstructive jaundice participates in their susceptibility to bacterial infection and tumor metastasis. Shock 33(5): 500-506, 2010.

9 Ljungdahl M, Osterberg J, Ransjö U, Engstrand L and Haglund $\mathrm{U}$ : Inflammatory response in patients with malignant obstructive jaundice. Scand J Gastroenterol 42(1): 94-102, 2007.

10 Coates JM, Beal SH, Russo JE, Vanderveen KA, Chen SL, Bold RJ and Canter RJ: Negligible effect of selective preoperative biliary drainage on perioperative resuscitation, morbidity, and mortality in patients undergoing pancreaticoduodenectomy. Arch Surg 144(9): 841-847, 2009.

11 Wang ZK, Xiao JG, Huang XF, Gong YC and Li W: Effect of biliary drainage on inducible nitric oxide synthase, CD14 and TGR5 expression in obstructive jaundice rats. World J Gastroenterol 19(15): 2319-2330, 2013.

12 Cunjin, GE: Effects of obstructive jaundice on intestinal mucosal barrier. Chinese J Gastroenterol Hepatol 20(10): 960-963, 2011.

13 Li D, Xie K, Wolff R and Abbruzzese JL: Pancreatic cancer: the lancet. Lancet 363(9414): 1049-1057, 2004.

14 Kuru B, Dinc S, Altinok G, Aksoz T, Camlibel M, Gulcelik MA and Alagol H: Effect of different enteral nutrients on bacterial translocation in experimental obstructive jaundice. EurSurg Res 36(1): 45-52, 2004.

15 Sewnath ME, Karsten TM, Prins MH, Rauws EJ, Obertop H and Gouma DJ: A meta-analysis on the efficacy of preoperative biliary drainage for tumors causing obstructive jaundice. Ann Surg 236(1): 17-27, 2002.
16 Schiavon AB, Muniz RM, Azevedo NA, Cardoso DH, Matos MR and Arrieira IC: Health workers coping with having a relative in palliative care for cancer. Rev GauchaEnferm 37(1): e55080, 2016.

17 van der Gaag NA, Rauws EA, van Eijck CH, Bruno MJ, van der Harst E, KubbenFJ, Gerritsen JJ, Greve JW, Gerhards MF, de Hingh IH, Klinkenbijl JH, Nio CY, de Castro SM, Busch OR, van Gulik TM, Bossuyt PM and Gouma DJ: Preoperative biliary drainage for cancer of the head of the pancreas. N Engl J Med 362(2): 129-137, 2010.

18 Qiu YD, Bai JL, Xu FG and Ding YT: Effect of preoperative biliary drainage on malignant obstructive jaundice: a metaanalysis. World J Gastroenterol 17(3): 391-396, 2011.

19 Ohshio G, Manabe T, Tamura K, Kudo H, Yoshioka H and Tobe T: Effects of percutaneous transhepatic biliary drainage on blood-bile permeability and selective $\operatorname{IgA}$ transport in patients with biliary obstructions. Ann Surg 211(4): 428-432, 1990.

20 Boullier S, Tanguy M, Kadaoui KA, Caubet C, Sansonetti P, Corthésy B and Phalipon A: Secretory IgA-mediated neutralization of Shigellaflexneri prevents intestinal tissue destruction by down-regulating inflammatory circuits. J Immunol 183(9): 5879-5885, 2009.

21 Bleier JI, Katz SC, Chaudhry UI, Pillarisetty VG, Kingham TP 3rd, Shah AB, Raab JR andDeMatteo RP: Biliary obstruction selectively expands and activates liver myeloid dendritic cells. J Immunol 176(12): 7189-7195, 2006.

22 Chou MH, Chuang JH, Eng HL, Chen CM, Wang CH, Chen CL, and Lin TM: Endotoxin and CD14 in the progression of biliary atresia. J Transl Med 8(1): 1-14, 2010.

23 Jones C, Badger SA, Black JM, McFerran NV, Hoper M, Diamond T, Parks RW and Taylor MA: The use of antiendotoxin peptides in obstructive jaundice endotoxemia.Eur J Gastroenterol Hepatol 24(3): 248-254, 2012.

24 Issaka RB, Shapiro DM, Parikh ND, Mulcahy MF, Komanduri $\mathrm{S}$, Martin JA and Keswani RN: Palliative venting percutaneous endoscopic gastrostomy tube is safe and effective in patients with malignant obstruction. SurgEndosc 28(5): 1668-1673, 2014.

25 Fang Y, Gurusamy KS, Wang Q, Davidson BR, Lin H, Xie X and Wang C: Meta-analysis of randomized clinical trials on safety and efficacy of biliary drainage before surgery for obstructive jaundice. Br J Surg 100(12): 1589-1596, 2013.

26 Sano T, Ajiki T, Takeyama Y and Kuroda Y: Internal biliary drainage improves decreased number of gut mucosal $\mathrm{T}$ lymphocytes and MAdCAM-1 expression in jaundiced rats. Surgery 136(3): 693-699, 2004.

27 Liu YJ, Mao EQ, Ouyang B, Chen J, Tang YQ, Huang SW and Guan XD: Effect of biliary tract external drainage on cytokine expression and histomorphology of intestine, liver, and lung in rats with hemorrhagic shock. Crit Care Med 37(10): 2800-2806, 2009.

Received May 19, 2017

Revised June 8, 2017

Accepted June 9, 2017 